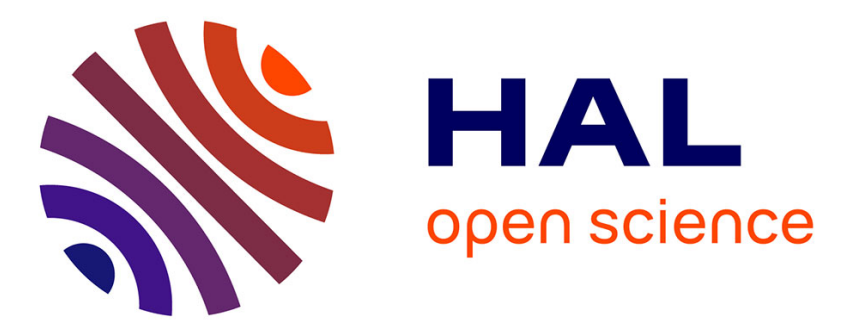

\title{
Modulation of Viscoelastic and Absorption Properties of Poly(vinyl alcohol)-graphene Oxide Composites
}

Yu Lei, Imane Boucenna, Véronique Thévenet, Diana Dragoe, Alain Ponton

\section{To cite this version:}

Yu Lei, Imane Boucenna, Véronique Thévenet, Diana Dragoe, Alain Ponton. Modulation of Viscoelastic and Absorption Properties of Poly(vinyl alcohol)-graphene Oxide Composites. ACS Applied Polymer Materials, 2021, 3 (9), pp.4717-4725. 10.1021/acsapm.1c00872 . hal-03411271

\section{HAL Id: hal-03411271 \\ https://hal.science/hal-03411271}

Submitted on 2 Nov 2021

HAL is a multi-disciplinary open access archive for the deposit and dissemination of scientific research documents, whether they are published or not. The documents may come from teaching and research institutions in France or abroad, or from public or private research centers.
L'archive ouverte pluridisciplinaire HAL, est destinée au dépôt et à la diffusion de documents scientifiques de niveau recherche, publiés ou non, émanant des établissements d'enseignement et de recherche français ou étrangers, des laboratoires publics ou privés. 


\section{Modulation of Viscoelastic and Absorption Properties of Poly(vinyl alcohol)-graphene Oxide Composites}

Yu Lei, Imane Boucenna, Véronique Thévenet, Diana Dragoe, and Alain Ponton*

Cite This: https://doi.org/10.1021/acsapm.1c00872

Read Online

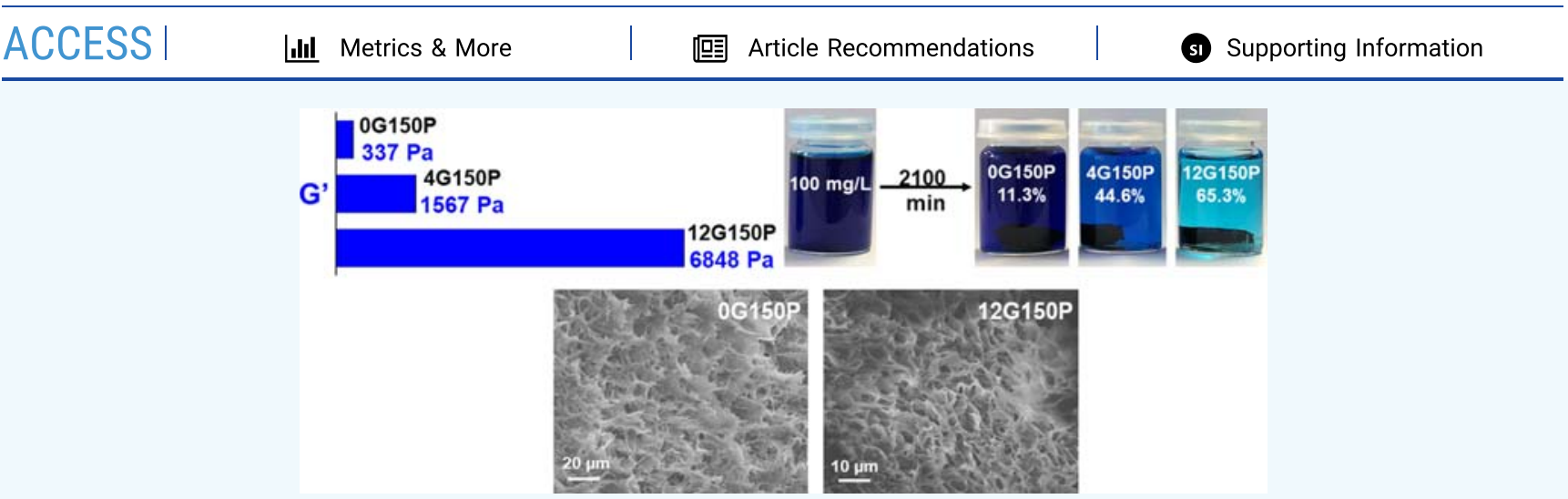

ABSTRACT: PVA (poly(vinyl alcohol))/GO (graphene oxide) composites were prepared by mixing the PVA aqueous solution and GO aqueous dispersion through the freezing-thawing method. The morphology and chemical structure of GO and composites were investigated by scanning electron microscopy and X-ray photoelectron spectroscopy, respectively. Viscoelastic and swelling properties and absorption capacities of cationic dye methylene blue (MB) were studied as a function of initial concentration of PVA and GO and the number of freezing-thawing cycles. The highest improvement in linear viscoelastic properties of PVA/GO composites was observed with the increase of GO concentration. Experimental data of the kinetic study of MB absorption were well fitted by the pseudo-first-order kinetic model and it was clearly shown that the greatest enhancement of MB absorption was also achieved by increasing the GO concentration. A correlation between swelling, absorption, and viscoelastic and structural properties of PVA/GO composites was proposed.

KEYWORDS: graphene oxide, poly(vinyl alcohol), polymer nanocomposites, rheology, absorption, swelling

\section{INTRODUCTION}

Graphene, a new kind of single-layer and two-dimensional carbon material, was first reported in $2001 .^{1}$ It has been widely investigated due to its excellent electrical conductivity, thermal stability, mechanical properties, and absorption ability, ${ }^{2-5}$ which make it ideal for a range of applications including sensors, batteries, supercapacitors, and composites. ${ }^{6-9}$ However, the dispersion of graphene is extremely low. ${ }^{10} \mathrm{GO}$ (graphene oxide), a precursor for graphene, possesses abundant negatively charged oxygen functional groups such as hydroxyl, epoxy, and carboxyl on the basal planes and edges, leading to a good dispersion and stable colloidal suspension in water or organic solvents. ${ }^{11}$ Meanwhile, these oxygencontaining groups make it possible to have strong interactions between the polymer and GO to prepare GO-based composites.

PVA (poly(vinyl alcohol)), a biocompatible and biodegradable polymer, can form an intriguing hydrogel through the freezing-thawing method without using traditional chemical cross-linking techniques, ${ }^{12}$ which has been applied in tissue engineering, biosensors, and controlled drug delivery sys- tems. ${ }^{13-15}$ However, its poor mechanical properties and lack of different kinds of functional groups (only existing hydroxyl groups) hinder the application, especially as an absorbent for dye removal. However, GO could effectively adsorb heavy metals and cationic dyes due to its high specific surface and abundant functional groups. ${ }^{16,17}$ Therefore, introducing GO into PVA matrix becomes a meaningful way to improve the mechanical strength and absorption ability. Zhang et al. prepared PVA/GO hydrogels by the freezing-thawing method; compared to the pure PVA hydrogels, a $132 \%$ increase in tensile strength and a $36 \%$ improvement of compressive strength was achieved with the addition of $0.8 \mathrm{wt}$ $\%$ GO into PVA hydrogels. ${ }^{18} \mathrm{Li}$ et al. proved that the interaction between GO and PVA matrix in both amorphous

Received: July 20, 2021

Accepted: August 5, 2021 
and crystal domains contributed to the improved mobility of PVA macromolecules and the increased dye absorption. ${ }^{19}$ Das et al. also reported the synthesis of hybrid hydrogel nanopolymer composites, referring to GO-impregnated chitosan-PVA hydrogel and its application to remove Congo red dye in solution. ${ }^{20}$

To better understand the relationship between mechanical properties and absorption behavior of PVA/GO composites, Xue et al. reported a series of PVA/GO composites synthesized by in situ assembly for 2 weeks. It was shown that gelation of PVA was promoted effectively with the increase of molecular weight of PVA or the addition of GO and the resulting PVA/GO xerogels could entrap the methylene blue (MB) molecule. ${ }^{21}$

To the best of our knowledge, no work has been reported so far in which elaboration, structural, viscoelastic, swelling, and absorption properties of PVA/GO composites were studied simultaneously. Therefore, to address this question in this work, PVA/GO composites were elaborated by the freezingthawing method to investigate the effects of PVA concentration, GO concentration, and the number of freezingthawing cycles on the viscoelastic, swelling, structural, and absorption properties.

Synthesized GO aqueous dispersion and PVA/GO composites were characterized by X-ray diffraction (XRD), X-ray photoelectron spectroscopy (XPS), and scanning electron microscopy (SEM). Viscoelastic, swelling, and absorption properties of PVA/GO composites were investigated as a function of PVA concentration, GO concentration, and number of freezing-thawing cycles. Based on the results, a possible relationship between viscoelastic properties and absorption behavior of PVA/GO composites was proposed. Consequently, based on rheological techniques, GO-based composites with excellent mechanical strength and high absorption capacity are potential to be designed as absorbents in practical applications.

\section{EXPERIMENTAL SECTION}

Materials. Graphite powder (maximum particle size: $75 \mu \mathrm{m}$ ) was purchased from GoodFellow (France). Concentrated sulfuric acid $\left(95 \%, \mathrm{H}_{2} \mathrm{SO}_{4}\right)$ and hydrochloric acid $(37 \%, \mathrm{HCl})$ were purchased from VWR International (France). Poly(vinyl alcohol) (PVA, $M_{\mathrm{w}}$ : $146000-186000$, alcoholysis degree: $99+\%)$, potassium permanganate $\left(\mathrm{KMnO}_{4}\right)$, hydrogen peroxide $\left(30 \%, \mathrm{H}_{2} \mathrm{O}_{2}\right)$, sodium nitrate $\left(\mathrm{NaNO}_{3}\right)$, and methylene blue (MB) were purchased from SigmaAldrich (Germany). All of the purchased chemicals were of analytical grade. Pure water was used during the experiments.

Synthesis of Aqueous GO Dispersions. GO was synthesized from natural graphite powder by modified Hummer's method. ${ }^{22}$ Briefly, concentrated $\mathrm{H}_{2} \mathrm{SO}_{4}(69 \mathrm{~mL})$ was added to a mixture of graphite flakes $(3 \mathrm{~g})$ and $\mathrm{NaNO}_{3}(1.5 \mathrm{~g})$ in an ice-water bath. After mechanical stirring for $1 \mathrm{~h}, \mathrm{KMnO}_{4}(9 \mathrm{~g})$ was added slowly during $2 \mathrm{~h}$ to avoid a rapid temperature rise and to maintain the reaction temperature below $20^{\circ} \mathrm{C}$. Then, the temperature was increased to 35 ${ }^{\circ} \mathrm{C}$ and maintained for $7 \mathrm{~h}$ with continuous mechanical stirring. Additional $\mathrm{KMnO}_{4}(9.0 \mathrm{~g})$ was added once and the mixture was stirred mechanically for $12 \mathrm{~h}$ at $35^{\circ} \mathrm{C}$. Subsequently, pure water (400 $\mathrm{mL}$ ) and $30 \% \mathrm{H}_{2} \mathrm{O}_{2}(30 \mathrm{~mL})$ were added when the reaction was cooled down to room temperature. After air cooling, the mixture was purified by dialysis for 2 weeks to remove the remaining metal species and acids. After ultrasonic treatment, GO aqueous dispersions with concentrations between 0.2 and $12 \mathrm{mg} / \mathrm{mL}$ were prepared by dilution from a mother concentrated dispersion $(10 \mathrm{mg} / \mathrm{mL})$ and ultracentrifugation (for $12 \mathrm{mg} / \mathrm{mL}$ ).
Preparation of PVA/GO Composites. PVA aqueous solution was prepared by dissolving the PVA powder in pure water at $95{ }^{\circ} \mathrm{C}$. PVA/GO composites were prepared with a mixture of PVA aqueous solutions and GO aqueous dispersions by the freezing-thawing method, which included a freezing step $\left(12 \mathrm{~h}\right.$ at $\left.-20^{\circ} \mathrm{C}\right)$ followed by a thawing step $\left(2 \mathrm{~h}\right.$ at $\left.25^{\circ} \mathrm{C}\right)$. PVA/GO composites were named as $x \mathrm{GyP}$ ( $x$ : GO concentration, $y$ : PVA concentration). For example, 4G150P was composed of $4 \mathrm{mg} / \mathrm{mL}$ GO and $150 \mathrm{mg} / \mathrm{mL}$ PVA and the volume ratio of GO and PVA was 1:1; if the number of freezingthawing cycles is not specified, one cycle is conducted.

Characterization studies. X-ray Diffraction (XRD) Measurements. The XRD profiles of graphite, GO, and PVA/GO composites were obtained with an X-ray diffractometer (PANalytical, EMPYREAI) in the range of $5-65^{\circ}$ with Co $\mathrm{K} \alpha$ radiation (1.542 $\AA$ ), a voltage of $45 \mathrm{kV}$, and an intensity of electrical current of $40 \mathrm{~mA}$.

$X$-ray Photoelectron Spectroscopy (XPS) Measurements. XPS measurements were performed on a $\mathrm{K}$ Alpha spectrometer from ThermoFisher, equipped with a monochromated X-ray Source ( $\mathrm{Al}$ $\mathrm{K} \alpha, 1486.6 \mathrm{eV}$ ) with a spot size of $400 \mu \mathrm{m}$. The hemispherical analyzer was operated in Constant Analyser Energy (CAE) mode, with a pass energy of $200 \mathrm{eV}$ and a step of $1 \mathrm{eV}$ for the acquisition of survey spectra, and a pass energy of 50 and $10 \mathrm{eV}$ and a step of $0.1 \mathrm{eV}$ for the acquisition of narrow spectra. A "dual beam" flood gun was used to neutralize the charge buildup. The obtained spectra were treated by means of Avantage software, provided by ThermoFisher and CasaXPS software. A Shirley-type background subtraction was used and the peak areas were normalized using the Scofield sensitivity factors. The binding energy scale was calibrated against the $\mathrm{C} 1 \mathrm{~s}$ main peak $(\mathrm{C}-\mathrm{O})$ binding energy set at $287.0 \mathrm{eV}$ in the case of $\mathrm{GO}$ and $284.8 \mathrm{eV}(\mathrm{C}-\mathrm{C})$ for PVA. The synthetic lineshapes were analyzed using mixed Gaussian-Lorentzian curves $(70 \%$ of Gaussian character). Lineshapes extracted from GO and PVA reference spectra $^{23,24}$ were used in the evaluation of PVA/GO ratio.

Scanning Electron Microscopy (SEM) Observations. Graphite and GO were dried at $40{ }^{\circ} \mathrm{C}$ for $24 \mathrm{~h}$, PVA/GO composites were freezedried for $24 \mathrm{~h}$ under vacuum. Then, all of the samples were coated by gold $(5 \mathrm{~nm})$ using a sputter coater. The morphology was observed using a scanning electron microscope (RAITH-PIONEER Two, Germany) at $10 \mathrm{kV}$.

$\zeta$ Potential Measurements. $\zeta$ Potentials of graphite and GO were determined by the dynamic light scattering technique (Brookhaven) from the measured electrophoretic mobility. The temperature was kept constant at $25^{\circ} \mathrm{C}$

Rheological Measurements. A torque-controlled rheometer (Fisher Scientific) with a parallel plate geometry $(1.5 \mathrm{~mm}$ gap and $20 \mathrm{~mm}$ diameter) was used. Before each measurement, the samples were maintained at $25{ }^{\circ} \mathrm{C}$. After loading the sample on the rheometer, a rest time of $20 \mathrm{~min}$ at $25^{\circ} \mathrm{C}$ was applied to eliminate the flow history and to reach temperature equilibrium. The exposed surfaces of PVA/ GO composites were surrounded by a solvent trap filled with pure water to prevent the evaporation during the experiment.

The linear viscoelastic region (LVR) was first determined by performing dynamic strain sweep from 0.1 to $1000 \%$ at a frequency of $0.1 \mathrm{~Hz}$. Then, the frequency dependences of storage modulus $\left(G^{\prime}\right)$ and loss modulus $\left(G^{\prime \prime}\right)$ were investigated by a dynamic frequency sweep from 0.01 to $10 \mathrm{~Hz}$ at a strain of $1 \%$.

Swelling Measurements. PVA/GO composites (around $1 \mathrm{~g}$ ) were immersed in pure water at $25^{\circ} \mathrm{C}$. The swollen samples were weighted at a predetermined time. The measurements were performed as triplicates. The swelling ratio was determined by the following equation

$$
\text { swelling ratio }=\frac{w_{t}}{w_{0}}
$$

where $w_{0}$ and $w_{t}$ are weights of original and swollen PVA/GO composites at time $t$, respectively.

Dye Absorption Measurements. Kinetic absorption was performed by introducing PVA/GO composites (around $1 \mathrm{~g}$ ) into methylene blue (MB) solution $(20 \mathrm{~mL}, 100 \mathrm{mg} / \mathrm{L})$. A UV-vis spectrophotometer (Jasco V-630, German) was used to analyze the 

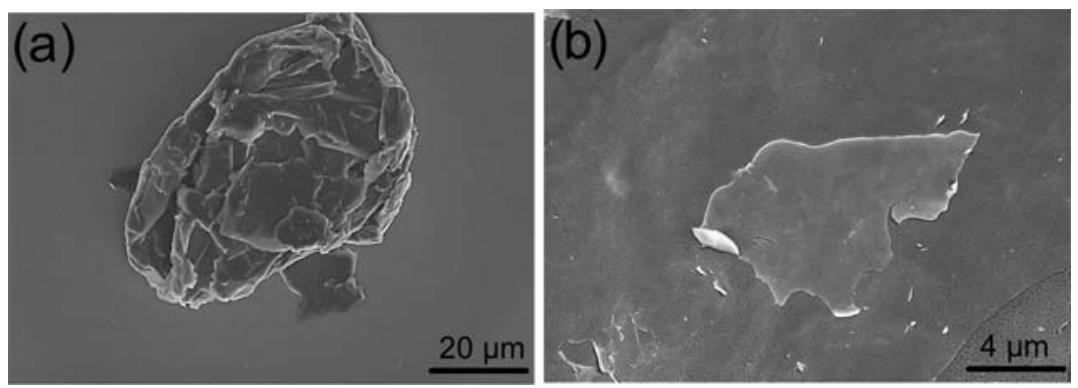

Figure 1. SEM images of (a) graphite and (b) GO.
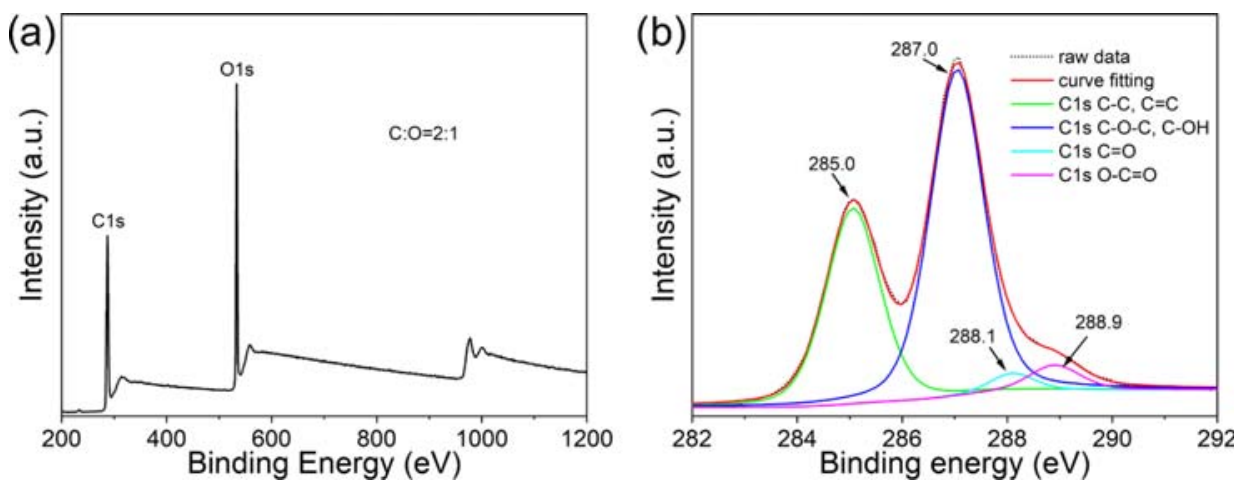

Figure 2. (a) XPS survey spectrum of GO and (b) C 1s XPS spectra of GO.

concentration of $\mathrm{MB}$ at a wavelength of $664 \mathrm{~nm}$. The absorption capacity of PVA/GO composites $(q, \mathrm{mg} / \mathrm{g})$ was calculated with the following equation

$$
q=\frac{V \times\left(C_{0}-C_{\mathrm{e}}\right)}{W}
$$

where $V(L)$ is the volume of $\mathrm{MB}$ solution, $C_{0}(\mathrm{mg} / \mathrm{L})$ and $C_{\mathrm{e}}(\mathrm{mg} / \mathrm{L})$ are the initial and equilibrium concentrations of $\mathrm{MB}$ solution, respectively, and $W(\mathrm{~g})$ is the weight of the sample.

\section{RESULTS AND DISCUSSION}

Characterization of Aqueous GO Dispersion. From $\zeta$ potential measurements, we can conclude that the high increase of $\zeta$ potential of GO $(-60.9 \mathrm{mV})$ which is maintained constant at $-60.3 \mathrm{mV}$ after 2 months, compared to that of graphite $(-1.91 \mathrm{mV})$ is the signature of the functionalization of GO and the stability of the dispersion during time.

The SEM images of graphite and GO are shown in Figure 1. Compared to the size of graphite in Figure 1a (about $100 \mu \mathrm{m}$ length and $50 \mu \mathrm{m}$ width), the size of GO in Figure $1 \mathrm{~b}$ (about $20 \mu \mathrm{m}$ length and $10 \mu \mathrm{m}$ width) decreases significantly, showing a sheet-like shape with single or several layers and some of them fold to induce wrinkles.

From the XRD patterns in Figure S1 in the Supporting Information, the peak of graphite shifted from 26.6 to $11.3^{\circ}$, corresponding to an increase of the interlayer distance $d$ from 3.3 to $9.0 \AA$ after oxidation, which is in a very good agreement with other reports. ${ }^{25}$

Figure 2a presents the XPS survey spectrum obtained for GO which clearly shows the presence of both carbon and oxygen in a ratio $2: 1$. The narrow scan obtained for $\mathrm{C} 1$ s corelevel spectrum is shown in Figure $2 b$ together with its components indicating the presence of neutral carbon (285.0 $\mathrm{eV}), \mathrm{C}-\mathrm{O}-\mathrm{C}$ and $\mathrm{C}-\mathrm{OH}(287.0 \mathrm{eV}), \mathrm{C}=\mathrm{O}(288.1 \mathrm{eV})$, and $\mathrm{O}-\mathrm{C}=\mathrm{O}(288.9 \mathrm{eV}){ }^{22,26}$ Based on these spectra, it can be concluded that GO is successfully synthesized and functionalized from graphite.

Characterization of PVA/GO Composites. In Figure S2 in the Supporting Information, the XRD diffraction peak for PVA hydrogel (0G150P) found at $2 \theta=19.5^{\circ}$ (interlayer distance $d=4.6 \AA$ ) referring to the strong inter- and intramolecular hydrogen bonding in PVA networks is also observed for PVA/GO composites without the appearance of other peaks, in particular, the one of GO at $2 \theta=11.3^{\circ}$ (Figure $S 1$ in the Supporting Information). These results suggest that GO are well-dispersed in PVA hydrogels without regular and periodic structures due to the potential interaction between hydroxyl groups of PVA and oxygen-containing groups of GO as reported by Usman et al. ${ }^{27}$

The $\mathrm{C} 1$ s core-level spectrum corresponding to pure PVA is shown as a reference in Figure $\mathrm{S} 3$ in the Supporting Information. The two components are $\mathrm{C}-\mathrm{C}(284.8 \mathrm{eV})$ and $\mathrm{O}-\mathrm{C}-\mathrm{O}(287.9 \mathrm{eV}){ }^{28}$ The C 1 s spectrum of PVA/GO composite (Figure 3) was fitted using the lineshapes extracted from GO and pure PVA used as references. The concentrations obtained in this way for PVA and GO are 96.4 and $3.6 \%$, respectively. These values are close to the experimental ones (94.9\% PVA and 5.1\% GO) of the composite elaboration.

Rheological Properties of PVA/GO Composites. The strain dynamic amplitudes of elastic $\left(G^{\prime}\right)$ and loss $\left(G^{\prime \prime}\right)$ moduli are shown in Figure 4 for different PVA concentrations (Figure $4 a)$, GO concentrations (Figure $4 \mathrm{~b}$ ), and number of freezingthawing cycles (Figure 4c). Two distinct regions are clearly seen for all of the curves.

In the first one named linear viscoelastic regime (LVR), both $G^{\prime}$ and $G^{\prime \prime}$ are independent of the applied strain $\gamma$ with $G^{\prime}>G^{\prime \prime}$ corresponding to a viscoelastic solid-like behavior. As the concentrations of PVA and GO or number of freezingthawing cycles are increased, viscoelastic moduli in LVR are increased. This enhancement of mechanical properties could 


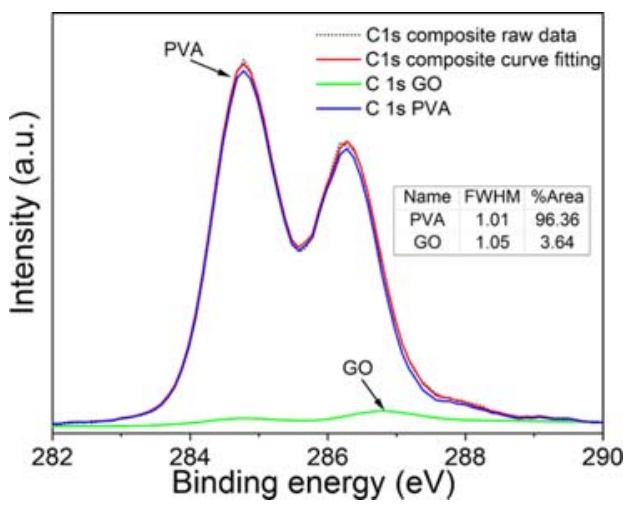

Figure 3. XPS spectra of C 1 s peaks of $8 \mathrm{G} 150 \mathrm{P}$.

be explained by more entanglements of PVA chains, stronger interactions between surface functional groups of GO sheets and PVA polymer chains as confirmed by XRD and XPS results, and the formation of PVA phase crystallite resulting in physical cross-linking of hydrogels, respectively. However, we can notice a saturation when the number of freezing-thawing cycles vary between 5 and 7 cycles.

In the second region above the linear viscoelastic regime, $G^{\prime}$ decreases from a critical strain, while $G^{\prime \prime}$ increases and reaches a peak value before decreasing.

The measurements have been performed twice for the samples for composites 0.2G150P, 0.8G150P, and 0.8G100P. We obtain a very good reproducibility within a maximum error bar of $5 \%$ in the linear viscoelastic domain.

The critical strain at nonlinearity begins to increase as PVA concentration is increased continuously. However, as GO concentration and number of freezing-thawing cycles are increased, the increase of the critical strain at nonlinearity is followed by a decrease from the sample $0.8 \mathrm{G} 150 \mathrm{P}$ and three cycles. This behavior known as "Payne effect" was already observed, in particular, in carbon black-filled elastomers, silica nanocomposites, and organoclay nanocomposites. ${ }^{29,30}$ It could be explained either by entanglement-disentanglement of polymer chains in case of colloidal fillers or by breakdown of the filler aggregates in case of organoclay fillers. Amplitude sweep measurements have been performed by increasing and decreasing strain values for the three studied parameters (PVA and GO concentrations, number of cycles). Globally, reversibility has been observed except for the most rigid PVA/GO composites for which breakdown of cross-linked clusters could be expected. For the other cases, nonlinearity could be explained by the capacity of these cross-linked clusters to deform and to move in large flows.

Figure 5 shows the frequency dependence of $G^{\prime}$ and $G^{\prime \prime}$ with the value of $G^{\prime}$ greater than the value of $G^{\prime \prime}$ over the range of measured frequency. This rubbery behavior has also been observed for PVA samples without GO and the mass between two entanglements $M_{\mathrm{e}}$ has been calculated from the plateau modulus $G_{N}{ }^{0}$ based on the analogy with rubber elasticity according to the equation

$$
M_{\mathrm{e}}=\frac{10^{3} C R T}{G_{N}^{0}}
$$

where $R$ is the gas constant, $C(\mathrm{mg} / \mathrm{L})$ is the concentration of PVA, and $T(\mathrm{~K})$ is the absolute temperature.

$G_{N}^{0}$ has been determined by the value of $G^{\prime}$ at a frequency where the ratio $G^{\prime \prime} / G^{\prime}$ attains a minimum value as proposed by Horinaka et al. ${ }^{31}$
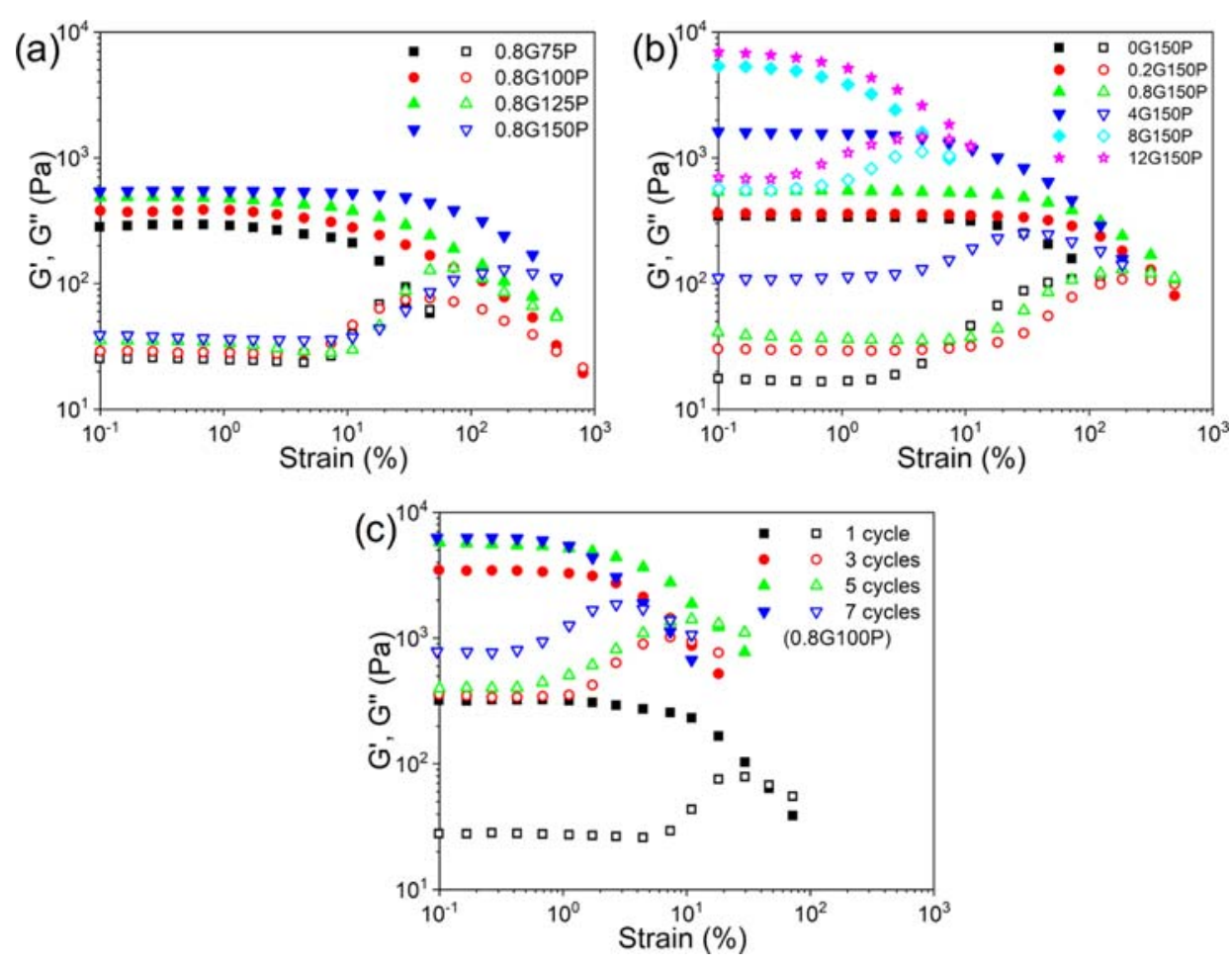

Figure 4. Strain dynamic amplitude dependence at constant frequency $(1 \mathrm{~Hz})$ of elastic $\left(G^{\prime}\right)$ and loss $\left(G^{\prime \prime}\right)$ moduli for different (a) PVA concentrations, (b) GO concentrations, and (c) number of freezing-thawing cycles (0.8G100P). Filled and open symbols for $G^{\prime}$ and $G^{\prime \prime}$, respectively. 

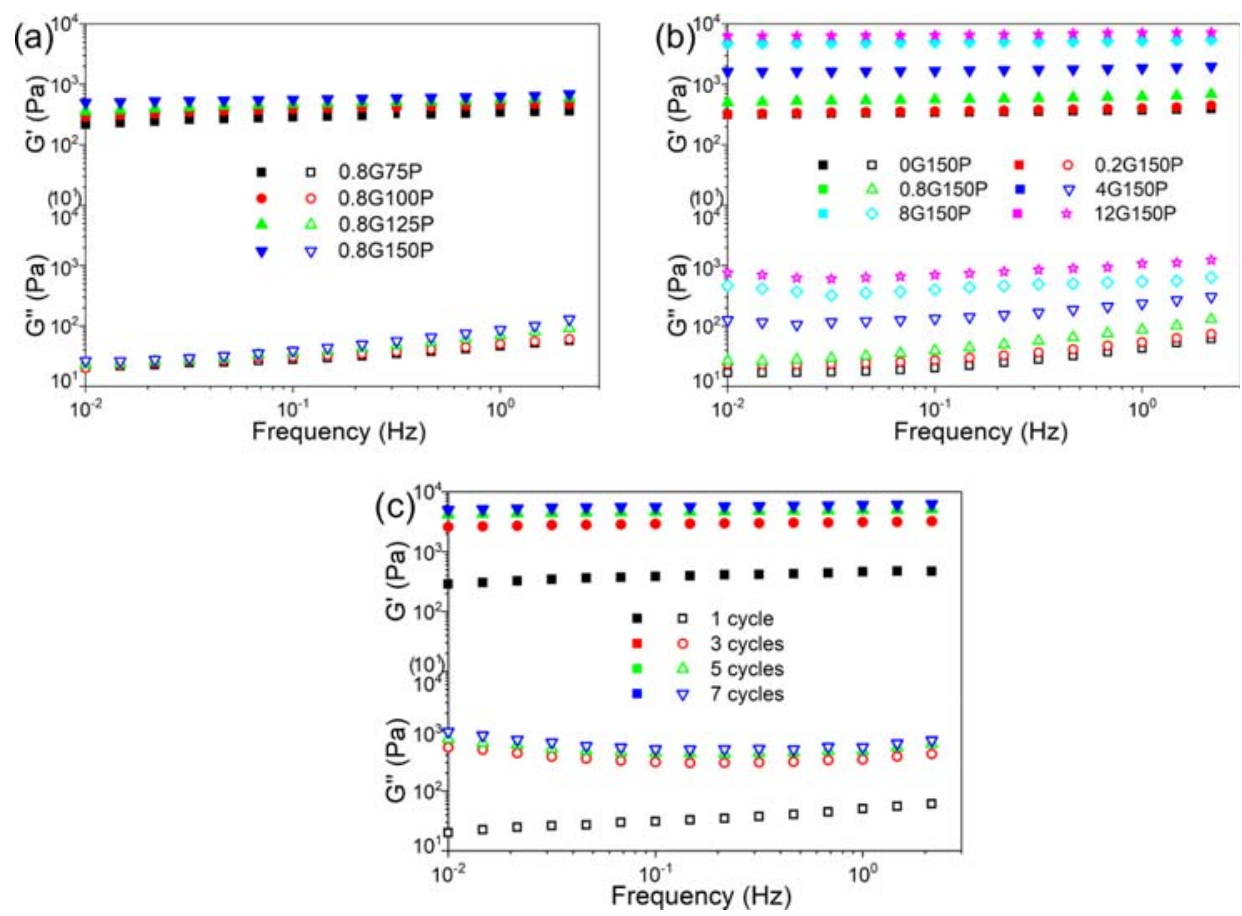

Figure 5. Frequency dynamic dependence at constant strain (1\%) of elastic $\left(G^{\prime}\right)$ and loss $\left(G^{\prime \prime}\right)$ moduli for different (a) PVA concentrations, $($ b) $\mathrm{GO}$ concentrations, and $(\mathrm{c})$ number of freezing-thawing cycles $(0.8 \mathrm{G} 100 \mathrm{P})$. Filled and open symbols for $G^{\prime}$ and $G^{\prime \prime}$, respectively.
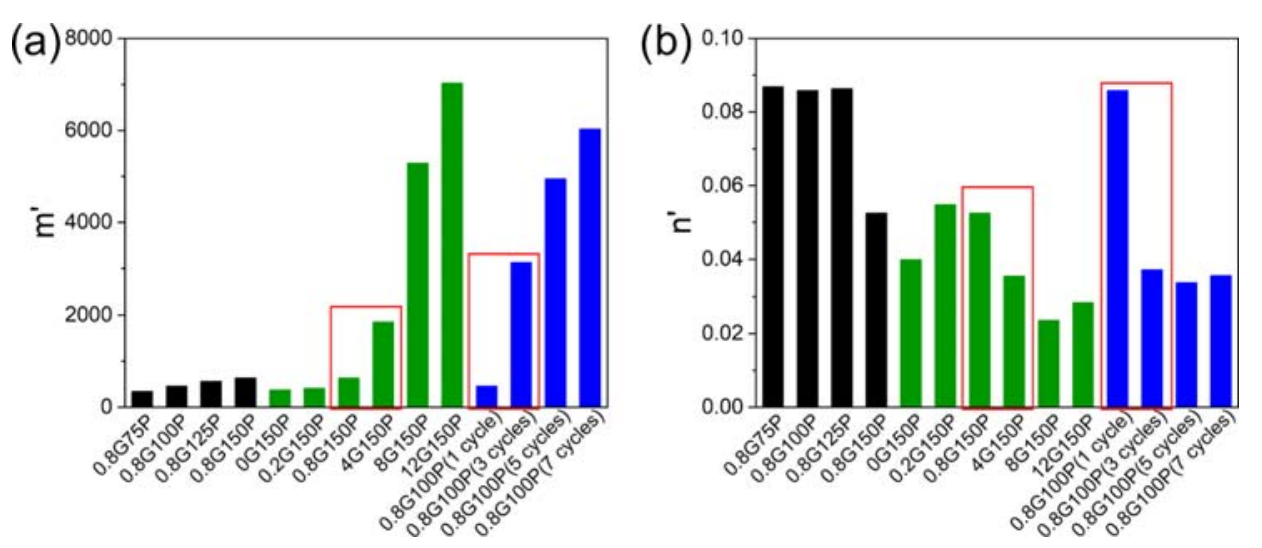

Figure 6. Fitted parameters (a) $m^{\prime}$ and (b) $n^{\prime}$ of power law frequency dependence of $G^{\prime}$ based on eq 4.

The values of $M_{e}$ for the PVA samples without $G O$ are between $293 \times 10^{4}$ and $110 \times 10^{4} \mathrm{~g} / \mathrm{mol}$ for the studied range of PVA concentrations (75P-150P). The introduction of GO in PVA samples induces an increase of $G_{N}{ }^{0}$ from $330 \mathrm{~Pa}$ (0G150P) to $6363 \mathrm{~Pa}(12 \mathrm{G} 150 \mathrm{P})$ and then a decrease of $M_{\mathrm{e}}$ from $110 \times 10^{4}$ to $6 \times 10^{4} \mathrm{~g} / \mathrm{mol}$ if we consider that eq 3 is valid for composites. In the same manner, increasing the number of freezing-thawing cycles from 1 to 7 decreases $M_{\mathrm{e}}$ from $84 \times 10^{4}$ to $4 \times 10^{4} \mathrm{~g} / \mathrm{mol}$.

Data of $G^{\prime}$ are then used to describe the solid-like behavior of composites, which is well fitted by a power law model that is generally used to describe the gel formation

$$
G^{\prime}(\omega)=m^{\prime *} \omega^{n^{\prime}}
$$

where $m^{\prime}$ is the consistency index and $n^{\prime}$ is the power law exponent.

The fitted parameters $m^{\prime}$ and $n^{\prime}$ are shown in Figure 6a,b, respectively. The most noticeable results are an increase of $m^{\prime}$ and a decrease of $n^{\prime}$ for the composites between 0.8G150P and 4G150P when GO concentration increases and the number of freezing-thawing cycles is varied between 1 and 3 cycles. These limits correspond to the ones for which the extent of LVR decreases as shown previously. In chemically cross-linked gels, the decrease of power low exponent was linked to an increase of cross-linking density at moderate polymer concentrations as described by Kjøniksen et al. ${ }^{32}$ For PVA/ GO composites, GO nanofillers could play the role of physical cross-linkers due to $\mathrm{H}$-bonding between PVA chains. ${ }^{33}$

Microstructure of PVA/GO Composites. As shown in Figure 7, SEM images reveal that PVA/GO composites are composed of three-dimensional (3D) porous networks. The pores of network become more regular with increasing PVA concentration as shown in Figure 7a (0.8G100P) and Figure $7 \mathrm{c}(0.8 \mathrm{G} 150 \mathrm{P})$. When GO concentration increases, the size scale of pores decreases from $10 \mu \mathrm{m}$ for $0.8 \mathrm{G} 150 \mathrm{P}$ (Figures $7 \mathrm{c}$ ) to $5 \mu \mathrm{m}$ for $12 \mathrm{G} 150 \mathrm{P}$ (Figure $7 \mathrm{~d}$ ), while it becomes larger but 

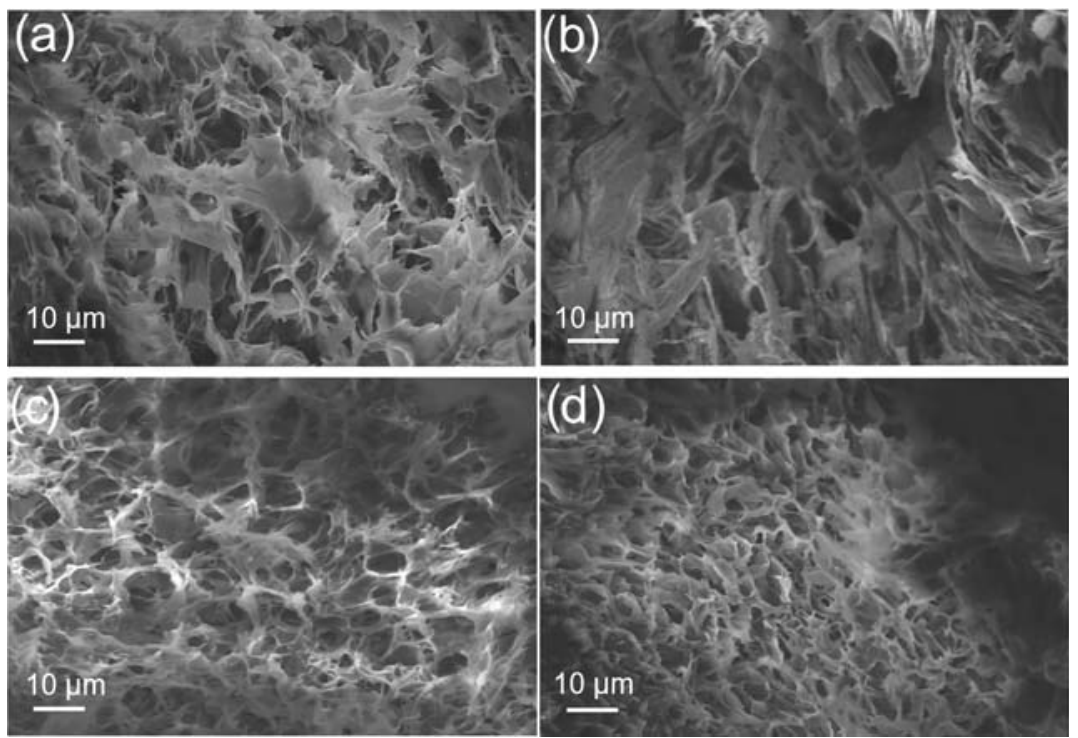

Figure 7. SEM images of PVA/GO composites: (a) 0.8G100P, (b) 0.8G100P (7 cycles), (c) 0.8G150P, and (d) 12G150P.
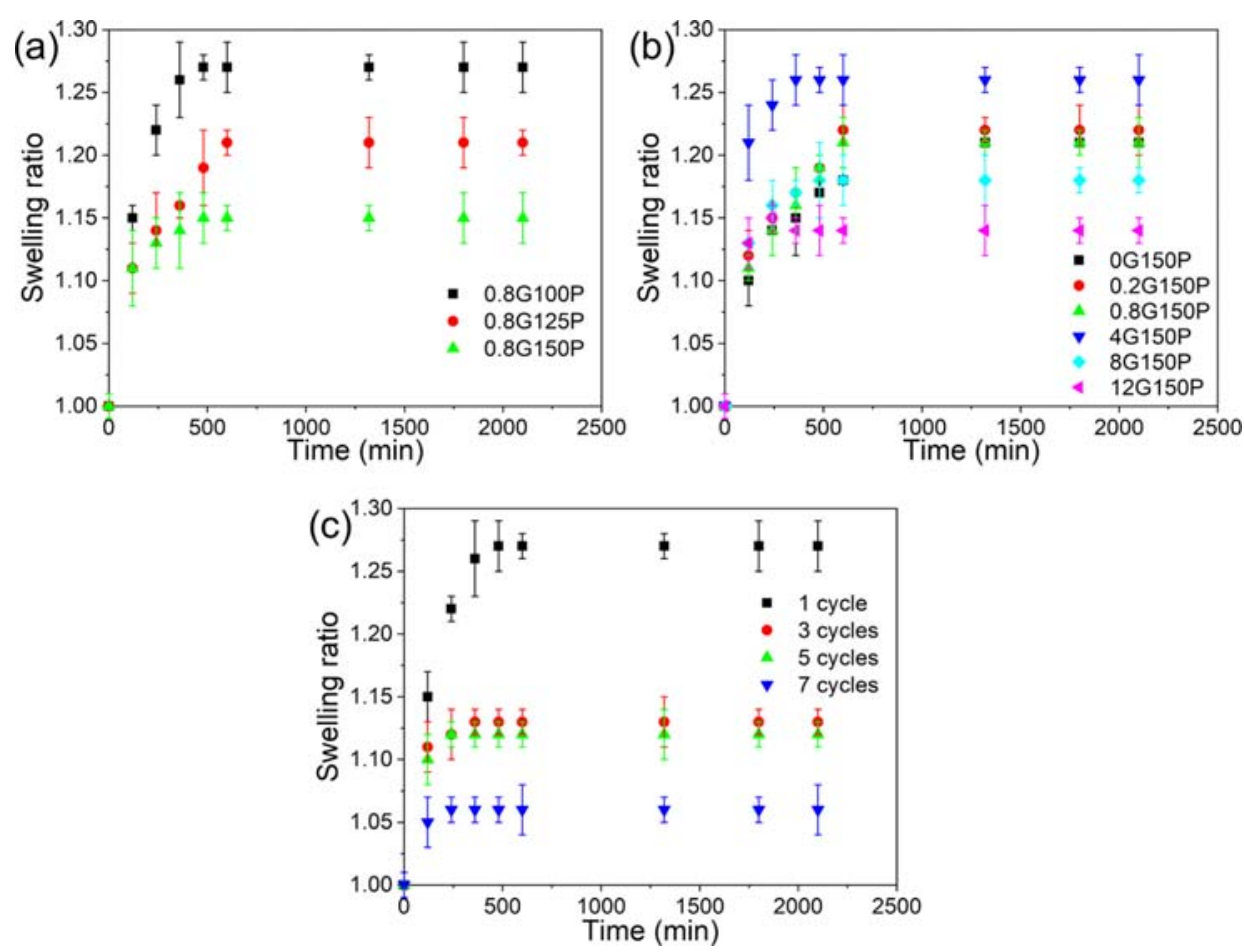

Figure 8. Effects of (a) PVA concentrations, (b) GO concentrations, and (c) number of freezing-thawing cycles (0.8G100P) on the swelling behavior of PVA/GO composites. The points and the error bars correspond to the average over three measurements and standard deviation, respectively.

thicker by increasing the number of freezing-thawing cycles from 1 cycle (Figure 7a) to 7 cycles (Figure 7b) for 0.8G100P.

Based on these observations, on the one hand, PVA provides the structural basis for the network and GO with oxygencontaining groups acting as cross-linkers in the PVA matrix. These cross-linkers form strong interactions between PVA and GO, such as hydrogen bonding, electrostatic, and Van der Waals interactions. The increase of GO concentration is beneficial to form a stronger network due to more cross-linkers associated to higher values of linear viscoelastic moduli. ${ }^{34}$ On the other hand, the increase of PVA concentration and number of freezing-thawing cycles seems to reinforce the existing PVA crystals, resulting in a higher crystallinity and change of structures. ${ }^{12}$

Swelling Process. As shown in Figure 8, the swelling rate is faster at the beginning and then slows down gradually for all studied samples except for $0.8 \mathrm{G} 75 \mathrm{P}$ which is destroyed during the swelling process. Globally, the swelling ratio decreases when the PVA concentration (Figure 8a) or the number of cycles (Figure 8c) increases. However, it increases when the GO concentration (Figure $8 \mathrm{~b}$ ) increases until 4G150P, and then a decrease is observed. Keeping in mind that GO is 
hydrophilic with oxygen-containing functional groups at the origin of the formation of hydrogen bonds between PVA and GO, the enhancement of swelling process could be associated to smaller pore size.

Dye Absorption. The digital images of $\mathrm{MB}$ solutions before and after absorption of PVA/GO composites are shown in Figure S4 in the Supporting Information as a macroscopic information. It is found that the increase of PVA concentration and number of freezing-thawing cycles has no discernible effect on the absorption of $\mathrm{MB}$, while the increase of GO concentration can remarkably enhance the absorption capacity.

More qualitative kinetic experiments are performed for all PVA/GO composites. An example of the results is shown in Figure 9. All results obtained by varying the three parameters

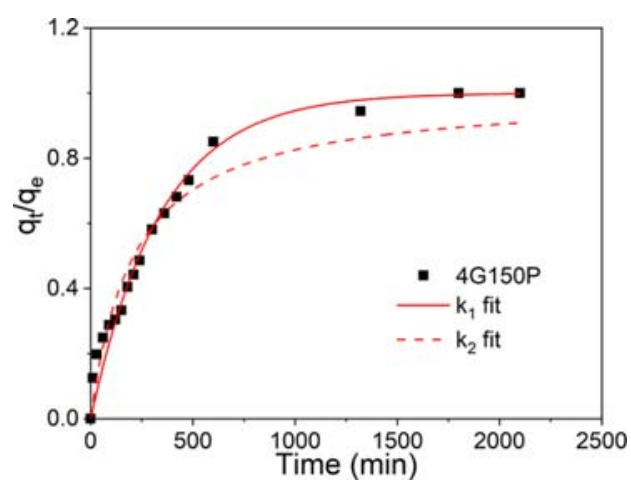

Figure 9. Methylene blue absorption kinetics for sample 4G150P Comparison of experimental data (points) by the pseudo-first-order model (solid line) and the pseudo-second-order model (dashed line).

(PVA concentration, GO concentration, number of freezingthawing cycles) are presented in Figure S5 in the Supporting Information. The absorption quantity of $\mathrm{MB}$ increases rapidly in the initial stage, and then slows down until the absorption process reaches equilibrium. Experiments of $\mathrm{MB}$ absorption kinetics are analyzed by pseudo-first-order and pseudo-secondorder kinetic models commonly used in the literature ${ }^{35}$

$$
\begin{aligned}
& \text { pseudo - first }- \text { order model: } \frac{q_{t}}{q_{\mathrm{e}}}=1-e^{\left(-k_{1} t\right)} \\
& \text { pseudo - second - order model: } \frac{q_{t}}{q_{\mathrm{e}}}=\frac{k_{2} q_{\mathrm{e}} t}{1+k_{2} q_{\mathrm{e}} t}
\end{aligned}
$$

where $q_{\mathrm{e}}$ and $q_{t}$ are the adsorbed $\mathrm{MB}(\mathrm{mg} / \mathrm{g})$ at equilibrium and at time $t$, respectively, $k_{1}\left(\mathrm{~min}^{-1}\right)$ and $k_{2}(\mathrm{mg} /(\mathrm{g} \min ))$ are the pseudo-first-order model rate constant and the pseudosecond-order model rate constant, respectively.

As explained by Jean-Pierre Simonin, fitting experimental data in which a significant number are close to equilibrium by the kinetic model with two open parameters may introduce errors. To overcome this drawback, it was proposed to fix $q_{\mathrm{e}}$ to experimental values. ${ }^{35}$ This methodology is used in our study and we can clearly show that the best agreement between experimental and fitted data is obtained with the pseudo-firstorder model (Figure 9).

From fitted data in Table 1 , the highest increase of absorption at equilibrium (or absorption efficiency) is obtained by the introduction of GO with a transition between $0.8 \mathrm{G} 150 \mathrm{P}$ and 4G150P, corresponding to an increase of rigidity and a decrease of the extent of LVR (see Figure 4). It is well known
Table 1. Fitted Parameters of Pseudo-First-Order Kinetic Model for the Absorption Behavior of MB on PVA/GO

\begin{tabular}{|c|c|c|c|c|}
\hline \multirow[b]{2}{*}{ samples } & \multicolumn{2}{|r|}{ experiment } & \multicolumn{2}{|c|}{$\begin{array}{l}\text { pseudo-first-order } \\
\text { model }\end{array}$} \\
\hline & $\begin{array}{c}q_{\mathrm{e}} \\
(\mathrm{mg} / \mathrm{g})\end{array}$ & $\begin{array}{l}\text { absorption efficiency } \\
(\%)\end{array}$ & $\left(10^{-3} \min ^{-1}\right)$ & $R^{2}$ \\
\hline $0.8 \mathrm{G} 100 \mathrm{P}$ & 0.42 & 20.9 & 4.6 & 0.98 \\
\hline $0.8 \mathrm{G} 125 \mathrm{P}$ & 0.44 & 22.3 & 5.3 & 0.99 \\
\hline $0.8 \mathrm{G} 150 \mathrm{P}$ & 0.45 & 22.6 & 5.8 & 0.95 \\
\hline 0G150P & 0.23 & 11.3 & 8.0 & 0.99 \\
\hline $0.2 \mathrm{G} 150 \mathrm{P}$ & 0.28 & 13.8 & 7.0 & 0.99 \\
\hline $0.8 \mathrm{G} 150 \mathrm{P}$ & 0.45 & 22.6 & 5.8 & 0.95 \\
\hline $4 \mathrm{G} 150 \mathrm{P}$ & 0.90 & 44.6 & 2.9 & 0.98 \\
\hline $8 \mathrm{G} 150 \mathrm{P}$ & 1.08 & 54.2 & 3.5 & 0.96 \\
\hline $12 \mathrm{G} 150 \mathrm{P}$ & 1.31 & 65.3 & 3.3 & 0.92 \\
\hline $\begin{array}{l}0.8 \mathrm{G} 100 \mathrm{P}(1 \\
\text { cycle) }\end{array}$ & 0.42 & 20.9 & 4.6 & 0.98 \\
\hline $\begin{array}{l}0.8 \mathrm{G} 100 \mathrm{P}(3 \\
\text { cycles) }\end{array}$ & 0.45 & 22.6 & 4.8 & 0.98 \\
\hline $\begin{array}{l}0.8 \mathrm{G} 100 \mathrm{P}(5 \\
\text { cycles) }\end{array}$ & 0.46 & 23.0 & 6.6 & 0.98 \\
\hline $\begin{array}{l}0.8 \mathrm{G} 100 \mathrm{P}(7 \\
\text { cycles) }\end{array}$ & 0.44 & 22.0 & 7.0 & 0.99 \\
\hline
\end{tabular}
Composites

that GO is negatively charged, PVA is a kind of nonionic polymer, ${ }^{36}$ and $\mathrm{MB}$ is a kind of typical cationic dye. In this case, the main enhancement of absorption capacity is attributed to the presence of strong interactions such as electrostatic and $\pi-\pi$ stacking interactions between GO and MB. Concerning the kinetics of absorption, the constant $k_{1}$ is the inverse of a characteristic time of kinetics $\left(\tau_{1}\right)$. Some general trends can be found between viscoelastic, swelling, and absorption results.

When the PVA concentration or the number of cycles increases, $\tau_{1}$ decreases slightly (faster kinetics of absorption) associated to no noticeable change of swelling ratio at equilibrium and viscoelasticity (especially for PVA concentration). On the contrary, when the GO concentration increases, we first observe a high increase of swelling ratio at equilibrium and $\tau_{1}$ (faster kinetics of absorption) until $0.8 \mathrm{G} 150 \mathrm{P}-4 \mathrm{G} 150 \mathrm{P}$ and second, a low increase of swelling ratio at equilibrium, while $\tau_{1}$ is rather constant. These findings are associated to the change of viscoelastic behavior (see Figure 6) from softer to harder composites.

\section{CONCLUSIONS}

PVA (poly(vinyl alcohol))/GO (graphene oxide) composites were elaborated by a mixture of PVA aqueous solution and aqueous GO dispersion through the freezing-thawing method by varying PVA concentrations, GO concentrations, and number of freezing-thawing cycles.

$\zeta$ Potential measurements confirmed the functionalization of GO and stability with time. The efficiency of exfoliation for GO and good dispersion of GO in PVA hydrogels was confirmed by X-ray diffraction (XRD) results.

On the basis of scanning electron microscopy (SEM) experiments, porous structures of composite PVA/GO were observed with mainly a decrease of the pore size when GO concentration was increased.

Viscoelastic behavior of PVA/GO composites investigated by small-amplitude oscillatory measurements showed that the increase of GO concentration mainly enhanced the mechanical 
properties as proved by the increase of linear viscoelastic moduli, strong nonlinearity behavior, and power law frequency dependence of elastic modulus. In the same way, the time equilibrium values of swelling ratio increased. Experimental data of the kinetic study of methylene blue (MB) absorption was well fitted by the pseudo-first-order kinetic model and it was clearly shown that the greatest enhancement of absorption was achieved by increasing the GO concentration, while the increase of PVA concentration or number of freezing-thawing cycles had no obvious effect.

Correlated results on swelling, absorption, and viscoelastic results indicate that GO concentration is the primary factor. It can be explained that on the one hand, the nonionic nature of PVA provides a stable structure through the freezing-thawing method for PVA/GO composites; on the other hand, negatively charged GO with oxygen functional groups act as cross-linkers for PVA/GO composites and interact with $\mathrm{MB}$ due to the hydrogen bonds and electrostatic interactions.

\section{ASSOCIATED CONTENT}

\section{SI Supporting Information}

The Supporting Information is available free of charge at https://pubs.acs.org/doi/10.1021/acsapm.1c00872.

XRD patterns of graphite and GO; XRD patterns of PVA/GO composites; XPS spectra of $C 1$ s peaks of pure PVA; macroscopic observation of methylene blue solutions before and after absorption of PVA/GO composites; and kinetic methylene blue absorption of PVA/GO composites by varying the three parameters (PVA concentration, GO concentration, number of freezing-thawing cycles) (PDF)

\section{AUTHOR INFORMATION}

\section{Corresponding Author}

Alain Ponton - Université de Paris, CNRS, Laboratoire Matière et Systèmes Complexes (MSC), F-75013 Paris,

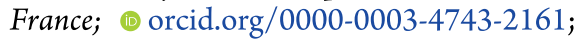

Email: alain.ponton@univ-paris-diderot.fr

\section{Authors}

Yu Lei - Université de Paris, CNRS, Laboratoire Matiere et Systemes Complexes (MSC), F-75013 Paris, France

Imane Boucenna - Université de Paris, CNRS, Laboratoire Matiere et Systèmes Complexes (MSC), F-75013 Paris, France

Véronique Thévenet - Université de Paris, CNRS, Laboratoire Matière et Systèmes Complexes (MSC), F-75013 Paris, France

Diana Dragoe - Université Paris-Saclay, CNRS, Institut de Chimie Moléculaire et des Matériaux d'Orsay (ICMMO), F91405 Orsay, France

Complete contact information is available at:

https://pubs.acs.org/10.1021/acsapm.1c00872

\section{Notes}

The authors declare no competing financial interest.

\section{ACKNOWLEDGMENTS}

The authors acknowledge the scientific and technical assistance of the Laboratory Interface Traitements Organisation et Dynamique des Systèmes (ITODYS)-Université de Paris for their provision of research facilities. This work was supported by the China Scholarship Council.

\section{REFERENCES}

(1) Novoselov, K. S. Electric Field Effect in Atomically Thin Carbon Films. Science 2004, 306, 666-669.

(2) Su, Y.; Lv, Y. Graphene and Graphene Oxides: Recent Advances in Chemiluminescence and Electrochemiluminescence. RSC Adv. 2014, 4, 29324-29339.

(3) Cong, H.-P.; Ren, X.-C.; Wang, P.; Yu, S.-H. Macroscopic Multifunctional Graphene-Based Hydrogels and Aerogels by a Metal Ion Induced Self-Assembly Process. ACS Nano 2012, 6, 2693-2703.

(4) Hou, W.; Tang, B.; Lu, L.; Sun, J.; Wang, J.; Qin, C.; Dai, L. Preparation and Physico-Mechanical Properties of Amine-Functionalized Graphene/Polyamide 6 Nanocomposite Fiber as a High Performance Material. RSC Adv. 2014, 4, 4848-4855.

(5) Perreault, F.; Fonseca de Faria, A.; Elimelech, M. Environmental Applications of Graphene-Based Nanomaterials. Chem. Soc. Rev. 2015, 44, 5861-5896.

(6) Hu, C.; Li, Z.; Wang, Y.; Gao, J.; Dai, K.; Zheng, G.; Liu, C.; Shen, C.; Song, H.; Guo, Z. Comparative Assessment of the StrainSensing Behaviors of Polylactic Acid Nanocomposites: Reduced Graphene Oxide or Carbon Nanotubes. J. Mater. Chem. C 2017, 5, 2318-2328.

(7) Liu, Z.; Wang, J.; Jia, X.; Li, W.; Zhang, Q.; Fan, L.; Ding, H.; Yang, H.; Yu, X.; Li, X.; Lu, B. Graphene Armored with a Crystal Carbon Shell for Ultrahigh-Performance Potassium Ion Batteries and Aluminum Batteries. ACS Nano 2019, 13, 10631-10642.

(8) Choi, H.; Nguyen, P. T.; Tran, C. V.; In, J. B. Micro-Patterned Metal Current Collectors for High Aspect Ratio Flexible Graphene Supercapacitors. Appl. Surf. Sci. 2020, 510, No. 145432.

(9) Yi, Y.; Sun, Z.; Li, C.; Tian, Z.; Lu, C.; Shao, Y.; Li, J.; Sun, J.; Liu, Z. Designing 3D Biomorphic Nitrogen-Doped MoSe2/Graphene Composites toward High-Performance Potassium-Ion Capacitors. Adv. Funct. Mater. 2020, 30, No. 1903878.

(10) Li, D.; Müller, M. B.; Gilje, S.; Kaner, R. B.; Wallace, G. G. Processable Aqueous Dispersions of Graphene Nanosheets. Nat. Nanotechnol. 2008, 3, 101-105.

(11) Liang, Y.; Wu, D.; Feng, X.; Müllen, K. Dispersion of Graphene Sheets in Organic Solvent Supported by Ionic Interactions. $A d v$. Mater. 2009, 21, 1679-1683.

(12) Hassan, C. M.; Peppas, N. A. Structure and Morphology of Freeze/Thawed PVA Hydrogels. Macromolecules 2000, 33, 24722479.

(13) Bi, S.; Pang, J.; Huang, L.; Sun, M.; Cheng, X.; Chen, X. The Toughness Chitosan-PVA Double Network Hydrogel Based on Alkali Solution System and Hydrogen Bonding for Tissue Engineering Applications. Int. J. Biol. Macromol. 2020, 146, 99-109.

(14) Yue, Y.; Gu, J.; Han, J.; Wu, Q.; Jiang, J. Effects of Cellulose/ Salicylaldehyde Thiosemicarbazone Complexes on PVA Based Hydrogels: Portable, Reusable, and High-Precision Luminescence Sensing of Cu2+. J. Hazard. Mater. 2021, 401, No. 123798.

(15) Long, J.; Etxeberria, A. E.; Kornelsen, C.; Nand, A. V.; Ray, S.; Bunt, C. R.; Seyfoddin, A. Development of a Long-Term Drug Delivery System with Levonorgestrel-Loaded Chitosan Microspheres Embedded in Poly(Vinyl Alcohol) Hydrogel. ACS Appl. Bio Mater. 2019, 2, 2766-2779.

(16) Wang, S.; Ning, H.; Hu, N.; Huang, K.; Weng, S.; Wu, X.; Wu, L.; Liu, J.; Alamusi. Preparation and Characterization of Graphene Oxide/Silk Fibroin Hybrid Aerogel for Dye and Heavy Metal Adsorption. Composites, Part B 2019, 163, 716-722.

(17) Sun, Y.; Chen, L.; Yu, J.; Yoon, B.; Lee, S. K.; Nam, J.-D.; Ci, L.; Suhr, J. Lightweight Graphene Oxide-Based Sponges with High Compressibility and Durability for Dye Adsorption. Carbon 2020, 160, 54-63.

(18) Zhang, L.; Wang, Z.; Xu, C.; Li, Y.; Gao, J.; Wang, W.; Liu, Y. High Strength Graphene Oxide/Polyvinyl Alcohol Composite Hydrogels. J. Mater. Chem. 2011, 21, 10399. 
(19) Li, C.; She, M.; She, X.; Dai, J.; Kong, L. Functionalization of Polyvinyl Alcohol Hydrogels with Graphene Oxide for Potential Dye Removal. J. Appl. Polym. Sci. 2014, 131, No. 398721.

(20) Das, L.; Das, P.; Bhowal, A.; Bhattachariee, C. Synthesis of Hybrid Hydrogel Nano-Polymer Composite Using Graphene Oxide, Chitosan and PVA and Its Application in Waste Water Treatment. Environ. Technol. Innovation 2020, 18, No. 100664.

(21) Xue, R.; Xin, X.; Wang, L.; Shen, J.; Ji, F.; Li, W.; Jia, C.; Xu, G. A Systematic Study of the Effect of Molecular Weights of Polyvinyl Alcohol on Polyvinyl Alcohol-Graphene Oxide Composite Hydrogels. Phys. Chem. Chem. Phys. 2015, 17, 5431-5440.

(22) Marcano, D. C.; Kosynkin, D. V.; Berlin, J. M.; Sinitskii, A.; Sun, Z.; Slesarev, A.; Alemany, L. B.; Lu, W.; Tour, J. M. Improved Synthesis of Graphene Oxide. ACS Nano 2010, 4, 4806-4814.

(23) Neal, F. CasaXPS Manual 2.3. 15: Introduction to XPS and AES. Casa Software 2009.

(24) d'Halluin, M.; Mabit, T.; Fairley, N.; Fernandez, V.; Gawande, M. B.; Le Grognec, E.; Felpin, F.-X. Graphite-Supported Ultra-Small Copper Nanoparticles - Preparation, Characterization and Catalysis Applications. Carbon 2015, 93, 974-983.

(25) Krishnamoorthy, K.; Veerapandian, M.; Yun, K.; Kim, S.-J. The Chemical and Structural Analysis of Graphene Oxide with Different Degrees of Oxidation. Carbon 2013, 53, 38-49.

(26) Shen, J.; Hu, Y.; Shi, M.; Lu, X.; Qin, C.; Li, C.; Ye, M. Fast and Facile Preparation of Graphene Oxide and Reduced Graphene Oxide Nanoplatelets. Chem. Mater. 2009, 21, 3514-3520.

(27) Usman, A.; Hussain, Z.; Riaz, A.; Khan, A. N. Enhanced Mechanical, Thermal and Antimicrobial Properties of Poly(Vinyl Alcohol)/Graphene Oxide/Starch/Silver Nanocomposites Films. Carbohydr. Polym. 2016, 153, 592-599.

(28) Watts, J. F. High Resolution XPS of Organic Polymers: The Scienta ESCA 300 Database. G. Beamson and D. Briggs. 280 pp., $£ 65$. John Wiley \& Sons, Chichester, ISBN 0471 935921, (1992): BOOK REVIEW. Surf. Interface Anal. 1993, 20, 267.

(29) Cassagnau, P. Payne Effect and Shear Elasticity of Silica-Filled Polymers in Concentrated Solutions and in Molten State. Polymer 2003, 44, 2455-2462.

(30) Cassagnau, P. Melt Rheology of Organoclay and Fumed Silica Nanocomposites. Polymer 2008, 49, 2183-2196.

(31) Horinaka, J.; Kimura, A.; Takigawa, T. Rheological Properties of Concentrated Solutions of Fucoidan in Water and in an Ionic Liquid. Polymer 2020, 211, No. 123090.

(32) Kjøniksen, A.-L.; Nyström, B. Effects of Polymer Concentration and Cross-Linking Density on Rheology of Chemically Cross-Linked Poly(Vinyl Alcohol) near the Gelation Threshold. Macromolecules 1996, 29, 5215-5222.

(33) Shi, Y.; Xiong, D.; Li, J.; Wang, N. In Situ Reduction of Graphene Oxide Nanosheets in Poly(Vinyl Alcohol) Hydrogel by $\gamma$ Ray Irradiation and Its Influence on Mechanical and Tribological Properties. J. Phys. Chem. C 2016, 120, 19442-19453.

(34) Shi, Y.; Xiong, D.; Li, J.; Wang, N. The Water-Locking and Cross-Linking Effects of Graphene Oxide on the Load-Bearing Capacity of Poly(Vinyl Alcohol) Hydrogel. RSC Adv. 2016, 6, 82467-82477.

(35) Simonin, J.-P. On the Comparison of Pseudo-First Order and Pseudo-Second Order Rate Laws in the Modeling of Adsorption Kinetics. Chem. Eng. J. 2016, 300, 254-263.

(36) Deng, S.; Xu, H.; Jiang, X.; Yin, J. Poly(Vinyl Alcohol) (PVA)Enhanced Hybrid Hydrogels of Hyperbranched Poly(Ether Amine) (HPEA) for Selective Adsorption and Separation of Dyes. Macromolecules 2013, 46, 2399-2406. 